\title{
Cohesion, sharing, and integration in Northern Ireland
}

\section{Colin Knox}

School of Criminology, Politics and Social Policy, University of Ulster, Shore Road, Jordanstown BT37 OQB, Northern Ireland; e-mail: cg.knox@ulster.ac.uk

Received 2 December 2010; in revised form 28 February 2011

\begin{abstract}
The devolved government in Northern Ireland pledged to work for a 'shared and better future for all' in its Programme for Government 2008-11. In pursuit of this goal it launched a consultation document entitled Programme for Cohesion, Sharing and Integration which challenged the assumption that division and segregation is a 'normal' pattern of living. I locate the policy proposals contained within the new programme in the research on community cohesion in Great Britain. I interrogate, using attitudinal data, people's preferences for the kind of society they want Northern Ireland to become and the policy consequences of their choices. Using two case studies in education and housing, I highlight the benefits of a shared society and question whether Northern Ireland can embrace the core elements of an intercultural society.
\end{abstract}

\section{Introduction}

Northern Ireland as a site of significant conflict and violence has come a long way. Key political developments in the form of The Belfast or Good Friday Agreement (1998) ushered in a democratically elected Assembly "inclusive in its membership, capable of exercising executive and legislative authority and subject to safeguards to protect the rights and interest of all sides of the community" (page 5). Devolution became a reality in December 1999 when the Northern Ireland Assembly and its Executive Committee of Ministers assumed powers of self-government under the Northern Ireland Act 1998 (Knox and Carmichael, 2005). However, there were faltering periods of devolution between 1999 and October 2002, at which point the Assembly was suspended for the fourth time due to a lack of trust and loss of confidence between key political stakeholders. With the eventual return to devolution in May 2007 (following the St Andrews Agreement), Northern Ireland is experiencing its first consistent period of devolved administrative stability in which the two key protagonists in the conflict [Democratic Unionist Party (DUP) and Sinn Féin] share executive and legislative powers.

Political parties claim key successes associated with devolution: free public transport is available to everyone over 60; local property taxes or rates have been frozen; proposed water charges have been postponed; prescription charges have been abolished; and there has been a major investment in infrastructure projects in schools, roads, and hospitals. Policing and justice, the so-called 'final piece in the devolution jigsaw, has been devolved (April 2010) to the Northern Ireland Assembly and all five main political parties operate a mandatory power-sharing coalition. To capture this political momentum, Derry (Londonderry) celebrated winning its bid to be the first UK City of Culture in 2013. This is not to suggest unbridled optimism. There remains a rump of dissident republican activists who have perpetrated acts of violence which appear to be escalating at the time of writing. Yet the long-term trend in violence is undoubtedly downwards: compare five recorded deaths due to the security situation in 2009 with 470 at the height of the 'troubles' in 1972 (PSNI, 2010). Northern Ireland has taken its share of the pain under UK-wide public expenditure cuts of $£ 6$ billion in 
2010/11 announced by the Conservative - Liberal Democrat coalition. Some $£ 130 \mathrm{~m}$ has been cut from the Northern Ireland budget ( $£ 10.3 \mathrm{~b}$ ) which will impact significantly on a region where over $30 \%$ of the total work force is employed in the public sector-total cuts over a four-year period $(2011-15)$ will amount to $£ 4$ billion.

Notwithstanding the significant political achievements in Northern Ireland, it remains a deeply segregated society. Around $90 \%$ of children attend either Protestant (controlled) or Catholic (maintained) schools; more than $70 \%$ of social housing estates are $90 \%$ single community occupied; and interface barriers between communities, or so called 'peace walls', have multiplied - in the Belfast area alone there are eighty-eight security and segregation barriers (Community Relations Council, 2009). To add to this culture of segregation and intolerance, racist incidents have increased from 813 in 2004/05 to 1038 in 2009/10 earning Northern Ireland the unenviable title of "race hate capital of Europe" (Chrisafis, 2004, page 1). Yet one of the key goals of the devolved government is to work towards "a shared and better future for all" (Northern Ireland Executive, 2008, page 6).

The aim of this paper is to examine what is meant by a 'shared and better future for all', a laudable goal but one which lacks reference to specific social and public policy priorities or wider research on community cohesion. I attempt to do this in a number of ways. First, I locate recent proposals for a shared and better future in a policy context and in the literature on community cohesion. Second, I interrogate, using attitudinal data, people's perception of 'normality' in Northern Ireland and the extent to which they see government playing an active role in encouraging a shared society. Finally, I consider two initiatives in education and housing which illustrate attempts to operationalise a shared and better future for Northern Ireland. I conclude with some thoughts on whether Northern Ireland is moving to an intercultural society. The intended contribution to the literature is twofold. At a conceptual level I interrogate the 'separate but equal' policy which underpins the highly segregated population that is Northern Ireland by drawing lessons from interculturalism which has its roots in Québec's policy of 'reasonable accommodation' and, more recently, a white paper on the same topic from the Council of Europe. At an empirical level, I conduct an analysis of survey data which explores future preferences for the kind of society Northern Ireland people want to live in.

\section{The policy context}

The most recent attempts to promote the goal of a shared and better future centred on two policy documents: A Shared Future (OFMdFM, 2005) and the consultation document Programme for Cohesion, Sharing and Integration (OFMdFM, 2010). The former was devised by British Ministers during the direct rule (from Westminster) era and the latter has emerged after protracted negotiations between Sinn Féin and the DUP who squabbled openly about its content.

The Shared Future policy document, drawing on extensive public consultation, argued that there was overwhelming support for a shared society in Northern Ireland (Hughes, 2009). Its underpinning principles were rooted in The Belfast or Good Friday Agreement (1998, page 18) which claimed that "an essential aspect of the reconciliation process is the promotion of a culture of tolerance at every level of society, including initiatives to facilitate and encourage integrated education and mixed housing." The policy document was emphatic in its tone:

"Separate but equal is not an option. Parallel living and the provision of parallel services are unsustainable both morally and economically ... . No one is arguing for an artificially homogeneous Northern Ireland and no one will be asked to suppress or give up their chosen identity. However, the costs of a divided society, whilst 
recognising, of course, the very real fears of people around safety and security considerations, are abundantly clear ..." (OFMdFM, 2005, page 15).

To illustrate the consequences of segregation, an empirical study was commissioned by the (direct rule) government to consider the financial cost of the Northern Ireland divide (Deloitte, 2007). The research concluded that an additional $£ 1.5$ billion per annum is spent on public services than a comparable region where such segregation did not exist. Set within the context of a $£ 10.3$ billion devolved budget $(2010 / 11)$, this is a major drain on public resources.

Despite the direct rule administration's commitment to A Shared Future and evidence of the high costs of a divided society, the policy was abandoned by the devolved Executive. Notwithstanding, the (then) First Minister (Ian Paisley) defended the role of his department, the Office of the First Minister and the deputy First Minister (OFMdFM), arguing that it was totally committed to promoting equality and human rights. More generally, Dr Paisley pointed to the fact that the Executive recognised the importance of creating a shared society through ministers' affirmation in their pledge of office that they will promote the interests of the entire country which are represented in the Northern Ireland Assembly and work towards the goal of a shared future. Sinn Féin argued against the whole basis of $A$ Shared Future claiming that it defined the primary problem as a lack of tolerance between communities particularly in socially deprived areas, rather than tackling disadvantage on the basis of objective need and addressing structural inequalities. It absolved the government from any responsibilities and redirected the problem towards the two main communities which were 'blamed' because they simply could not coexist. A Shared Future became a casualty of policies tainted by association with the direct rule era which the devolved government was keen to distance itself from and start afresh.

It is within this context that the OFMdFM (2010) launched a consultation document Programme for Cohesion, Sharing and Integration which set out the Northern Ireland Executive's vision for the future by challenging the assumption that division and segregation is a 'normal' pattern of living. The junior minister in the OFMdFM announced at the launch:

"Cohesion, Sharing and Integration will be the catalyst to make a difference to the lives of people and the experiences of communities across our society. We will also provide and expand shared spaces and services and tackle all forms of hate crime and intimidation. We will work together to build a society where people can live, work and socialise in safe, shared and accessible facilities. We want a future based on sharing, equality, respect and understanding" (Kelly, 2010, page 1).

The document lists a number of goals for achieving a shared and better future for all. The intention is that the OFMdFM will drive the agenda by coordinating input from all government departments and agencies (eg district councils, community, and voluntary sector) involved in its delivery. The importance attached to the programme by the Executive is signalled by the fact that its implementation will be overseen by a ministerial panel chaired by OFMdFM ministers, and key statutory and community partners, and cross-departmental activities will be coordinated through a senior officials' steering group.

Notwithstanding the responses to the consultation process, the Executive lists a number of 'themes for action which are already clear'. These include:

- Ensuring that good relations considerations are embedded within all government policy making.

- Reducing and eventually eliminating segregated services.

- Addressing interfaces and encouraging shared neighbourhoods. 
Responses to the government's proposals have been mostly negative-best captured by one political commentator who described them as "aspirational or motherhood and apple pie" (Davenport, 2010). This reaction reflects wider criticism that Cohesion, Sharing and Integration fails to set targets or dates for measurable progress and does not mention any financial commitment on the part of government. As one newspaper editorial described it: "the proposed programme suggests that the Executive has set out to manage, rather than eradicate, sectarianism" (Irish News 2010, page 10). In short, it is a woolly benign document and one which offers little by way of specific and measurable objectives, policy priorities, or an implementation strategy. It is the product of a political consensus between the DUP and Sinn Féin replete with good intentions but lacking in specificity.

\section{The literature}

Although billed as a consultation document on Cohesion, Sharing and Integration (OFMdFM, 2010), it is surprising that there is no mention of the wider political and academic discourse on social cohesion both within Great Britain and beyond. It offers no definitions of what the key terms mean or a contextual analysis of the problems of segregation in Northern Ireland. The document is wholly insular. One can only assume that there is, given the title, some reference to the debate on community cohesion in Great Britain which followed the street disturbances in Bradford, Burnley, and Oldham in 2001 (Conway, 2009; Eatwell, 2006, Flint and Robinson, 2008; Gavrielides, 2010; Harris and Young, 2009; Kalra and Kapoor; 2009; Thomas, 2007; Worley, 2005). The outbreak of violence, stoked by National Front activities, involved racial abuse between whites and young Asian men that led to stabbings and police using riot control measures (Denham, 2001; Ouseley, 2001). A report into the causes of these disturbances found that people were living 'parallel lives' and recommended ways to tackle segregation and promote community cohesion:

"Separate educational arrangements, community and voluntary bodies, employment, places of worship, language, social and cultural networks, means that many communities operate on the basis of a series of parallel lives. These lives often do not seem to touch at any point, let alone overlap and promote any meaningful interchanges" (Community Cohesion Independent Review Team, 2001, page 9).

Self-segregation, according to Cantle (the Chair of the review team), did not provide the basis for a harmonious community and unless this was addressed it would lead to more serious problems in the long term.

The Cantle report also made the point, however, that ethnic segregation was also an issue in nonfaith schools. These claims of self-segregation have been robustly challenged by Finney and Simpson (2009) who disagreed that the extent of separation by religious affiliation or ethnic identity in Britain amounted to parallel lives. They argued that this presupposed an unwillingness on the part of minorities to integrate which encouraged cultural conflict, yet their research evidence disproved this assertion. They challenged the Commission for Racial Equality's assertion (2005) that Britain is "sleepwalking to segregation" (young people from ethnic minorities were twice as likely to have a circle of friends exclusively from their own community) as "alarmist language and false claim to scientific rigour to create a striking message about friendship groups, unsupported by the evidence, of dangerous inward-looking communities, harbingers of a bleak future for the UK" (Finney and Simpson, 2009, page 99). In a critique of their work Cantle (2009) argued that trends in segregation cannot be definitively concluded because the 2001 Census data are out of date and other recent research is too limited to draw conclusions. 
The parallel-lives quotation (above) could apply in equal measure to Northern Ireland today where segregation is the norm. Shirlow and Murtagh (2006) describe a number of social factors which impact on the nature of segregation in Northern Ireland - in particular, interface communities. Few people worked and travelled in areas dominated by the 'other' community, the latter for fear of being attacked. In some cases people wanted to 'support' their own community by spending money therein-shopping elsewhere could be seen as being disloyal. In addition, "there is a real sense of prejudice and a desire to reduce the potential for contact with the 'other' community" (page 90). Are there lessons from Britain's experience of community cohesion?

The community cohesion debate has evolved since 2001 and been sustained by more recent issues around immigration policy, the electoral success of the far-right party (British National Party), and the fraught relationship between Islamic and British identity (Flint, 2010). The discourse on community cohesion has widened and led to a fundamental rethink on addressing the whole issue of cultural diversity. The model of assimilation which suggested that minorities should adapt the predominant ethos moved to one where cultures and religions could peacefully coexist. This evolved into multiculturalism whereby minority cultures are considered equal to that of the majority community and separation, rather than assimilation, was deemed acceptable. Community cohesion was seen as a move away from multiculturalism in which coexistence resulted in some communities living in isolation with little or no interaction. A more recent contribution to the narrative has been provided by the Council of Europe which espouses a policy of interculturalism.

The terms multiculturalism and interculturalism require explication here. Todd (1994, page 216) argues that multiculturalism is "the harmonious coexistence of differing cultural or ethnic groups in a pluralist society." Multicultural public policies aim to "maintain harmony between diverse ethnic groups and structure the relationships between the state and ethnic minorities." Yet Rex (2010, page 217) argues that the meaning of a multicultural society in Britain today "remains remarkably obscure". Kymlicka (2010) charts the rise of, and retreat from, multiculturalism which in summary covers two broad phases of development. From 1970s to mid-1990s there was "a trend towards recognition and accommodation of diversity through policies and minority rights." Since then, there have been "fears amongst the majority group that accommodation of diversity has gone too far and is threatening their way of life" (page 97). He concludes that efforts at promoting multiculturalism were often naive and its critique is largely 'off target' because of the lack of attention to the conditions for successful implementation.

This theme has been taken up recently by UK Prime Minister, David Cameron, when he declared that multiculturalism has failed, echoing similar statements by Nicolas Sarkozy and Angela Merkel, arguing years of "hands-off tolerance" have encouraged different cultures to live separate lives and created a fear of standing up to the racism of minorities. He declared that "we need a lot less passive tolerance of recent years and a much more active muscular liberalism" (Wright and Taylor, 2011, page 1). In response, Mahood (2011) argued that, despite notices of the death of multiculturalism in the UK, heralded as far back as 1989 by the Salman Rusdie Satanic Verses affair, it has flourished with the sanctioning of faith schools, religious discrimination legislation, and bringing Muslims into the networks of governance. Mahood suggested that "we must not take for granted what we have in common, but work hard to ensure that all citizens recognise themselves in our shared concept of citizenship" (page 32). 
Interculturalism has its roots in the Québec government's policy of integration and is different from multiculturalism adopted since the early $1970 \mathrm{~s}$ by other parts of Canada. Multiculturalism as a model was not considered suitable for Québec because "in English Canada there is less concern for the preservation of a founding cultural tradition than for national cohesion" (Bouchard and Taylor, 2008, page 39). A commission was set up in Quebec in 2007 to examine public discontent over 'reasonable accommodation' practices related to cultural differences. The commission argued that integration is a key component in Québec's interculturalism model. In defining interculturalism it noted, inter alia:

"In a spirit of reciprocity, interculturalism strongly emphasizes interaction, in particular intercommunity action, with a view to overcoming stereotypes and defusing fear or rejection of 'the other', taking advantage of the enrichment that stems from diversity, and benefiting from social cohesion" (page 40).

In Europe this debate has been given focus through a white paper on intercultural dialogue which asserts that "old approaches to the management of cultural diversity were no longer adequate" (Council of Europe, 2008, page 9). The white paper goes on to argue: "whilst driven by benign intentions, multiculturalism is now seen by many as having fostered communal segregation and mutual incomprehension." Instead, it suggests combining elements of both into an emerging interculturalist approach which: "takes from assimilation the focus on the individual and from multiculturalism the recognition of cultural diversity. And it adds the new element, critical to integration and social cohesion, of dialogue on the basis of equal dignity and shared values" (page 19).

Two aspects of the community cohesion debate in Britain have particular resonance with emerging policies on tackling segregation in Northern Ireland-integrated or shared education and mixed social housing. Cantle (2001) criticised the wisdom of faith-based schools on the basis that outside of their homes education has a significant influence on the lives of children. He recommended that at least $25 \%$ of places at faithbased schools should be available to children of other faiths or none. This has not happened; instead there has been an expansion of faith schools in Great Britain mainly through the academy scheme. Proponents argue such an expansion is in response to demands for greater parental choice; opponents claim faith schools lead to greater segregation and deeper divisions within communities. The Conservative-Liberal Democrats coalition government has reignited this debate under recent plans for parents, teachers, charities, and faith groups to put in bids to run their own schools, opening the door for the creation of more faith schools.

Research evidence from Great Britain on the experience of education and housing in promoting community cohesion offers important lessons for Northern Ireland, not least its tendency to ignore middle-class patterns of segregation and polarisation in where they live and have their children educated (Amin, 2002; Phillips 2006). Flint (2007) examined parallel developments in Catholic state schools in Scotland and the Muslim state sector in England. He argued that minorities found it difficult to contribute to definitions of a cohesive national identity and 'legitimate' citizenship. Faith schools were therefore "an important element of the institutional architecture that enables cultural identities to flourish and be protected" (page 264). He refered to measures to ameliorate the effects of religious and ethnic segregation effects on the state education system (such as interschool twinning, better teacher training on diversity issues) and concluded that "faith schools simultaneously contribute to and undermine different dimensions of community cohesion" (page 264).

Robinson (2005) examined the role of mixed housing as a way of promoting community cohesion and questioned a number of assumptions which underpinned such a 
policy response. He considered, inter alia, the role that housing policy and provision might play in promoting increased ethnic mix and the benefits of social interaction assumed to flow from residential integration. Robinson drew attention to the constrained choices which inhabitants of segregated communities have-minority ethnic groups are more likely to live in socially deprived areas, be unemployed, and experience poor health. The same is true in Northern Ireland. There is evidence that segregation is correlated with levels of deprivation. Fourteen of the fifteen most deprived areas in Belfast are highly segregated (OFMdFM, 2010, page 19). Robinson's research in England concluded that "it is questionable whether housing policy can effect change in residential settlement patterns and promote increasing interethnic mix at the neighbourhood level" (2005, page 1425). In addition, he claimed that "even if interethnic residential integration can be actively promoted, it cannot be assumed that interethnic interaction will inevitably follow."

Robinson also criticised the wider community cohesion agenda: "[it] has overblown differences of ethnicity, is unwarranted in maintaining that the problem is with minority ethnic communities and is wrong in many of the conclusions drawn to legitimatise the specifics of the policy response" (page 1412). Burnett $(2004 ; 2007)$ echoed these criticisms by arguing that the "ideological basis of community cohesion is exclusionary" in that the state has abdicated its responsibilities for fractured communities and through community cohesion strategies shifted the onus back onto communities to deal with problems originating from government neglect (Burnett, 2004, page 15). Flint (2010, page 261) summarised the critique by arguing that "the concept of community cohesion has been subject to sustained criticism due to its alleged de-politicisation of race, its limiting concept of cohesion and its assimilationist tendencies."

\section{Empirical analysis}

Is the Northern Ireland consultation document Cohesion, Sharing and Integration (OFMdFM, 2010) therefore based on a discredited or at least passé premise for community cohesion? A missing element in the devolved government's proposals for cohesion, sharing, and integration is an assessment of people's attitudes to a postconflict policy and whether we are moving from a segregated society which acknowledges and protects the separate interests of the two main communities in Northern Ireland to a new form of interculturalism (Amin, 2002). Is the government actively encouraging greater sharing? Will moves towards greater 'mixing' improve community cohesion and, if so, what should the public and social policy priorities be to make this happen? In an effort to make a contribution to this policy debate generated through the publication of Cohesion, Sharing and Integration, I interrogate public attitudes to these questions and report the analysis below in direct response.

My methodology is to conduct a secondary analysis using data from the 2009 Northern Ireland Life and Times survey to explore the questions posed above. The survey sample size is 1089 respondents aged 18 or over selected using systematic random sampling and the data were collected between October and December 2009. (1) The sampling frame for participant selection is addresses from the register of the Land and Property Services Agency in the Northern Ireland Department of Finance and Personnel. This is the most up-to-date listing of private households and is made available through to the Northern Ireland Statistics and Research agency for research purposes. Interviewers listed all members of the households eligible for inclusion and randomly selected one adult per household in the sample. The margin of error for all sample estimates is within the parameters of $\pm 2.8 \%$. 
(a) How do people perceive Northern Ireland?

The Northern Ireland Life and Times Survey (2009) asked respondents their reactions to a number of statements with the preamble "people have ideas for the kind of society Northern Ireland should become". Respondents were then asked whether they thought listed ideas had been achieved, one of which was as follows:

"Northern Ireland is a normal civic society in which all individuals are equal, where

differences are resolved through dialogue and where all people are treated impartially." In each case respondents were asked to score their answers on a scale ranging from 1 to 10, where:

$1=$ it has definitely not been achieved,

$10=$ it definitely has been achieved.

The results of this question are displayed in figure 1.

The variable 'normal civic society' is slightly positively skewed (skewness $=0.063$ ) with scores clustered at the lower end of the scale as indicated by the trend line. This suggests that people are less inclined to the view that "Northern Ireland is a normal civil society in which all individuals are equal" with a mean value of 4.54 on a ten-point scale and standard deviation of 2.1.

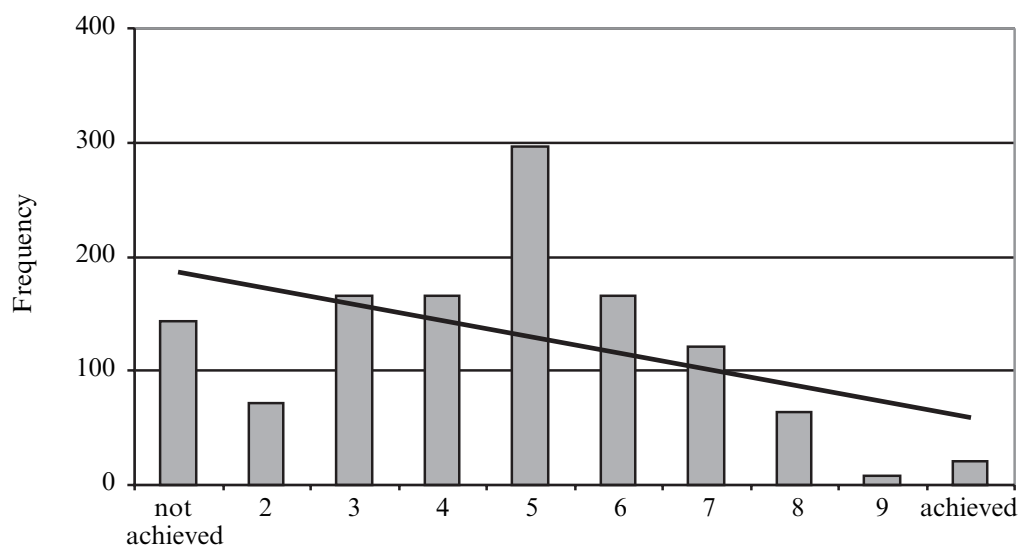

Notes: $N=1222 ;$ mean $=4.54 ;$ standard deviation $=2.099$.

Figure.1. A normal civic society?

(b) Is the government encouraging a shared society?

Respondents were asked their opinion on the role which government was playing in relation to promoting a shared society in Northern Ireland. The survey outlined the following statement and sought respondents' views on the extent to which this had been achieved:

"The government is actively encouraging shared communities where people of all backgrounds can live, work, learn and play together."

The results are displayed in figure 2 .

The variable 'government encouraging a shared society' is slightly negatively skewed (skewness $=-0.081$ ) with scores clustered marginally at the higher end of the scale as indicated by a flattish trend line. This suggests that people are fairly evenly balanced on the view that "government is actively encouraging shared communities" with a mean value of 5.52 on a ten-point scale and standard deviation of 2.14.

Overall, therefore, respondents tended to think that, on balance, Northern Ireland is not yet a normal civic society and that government is, to a limited extent, "encouraging shared communities". 


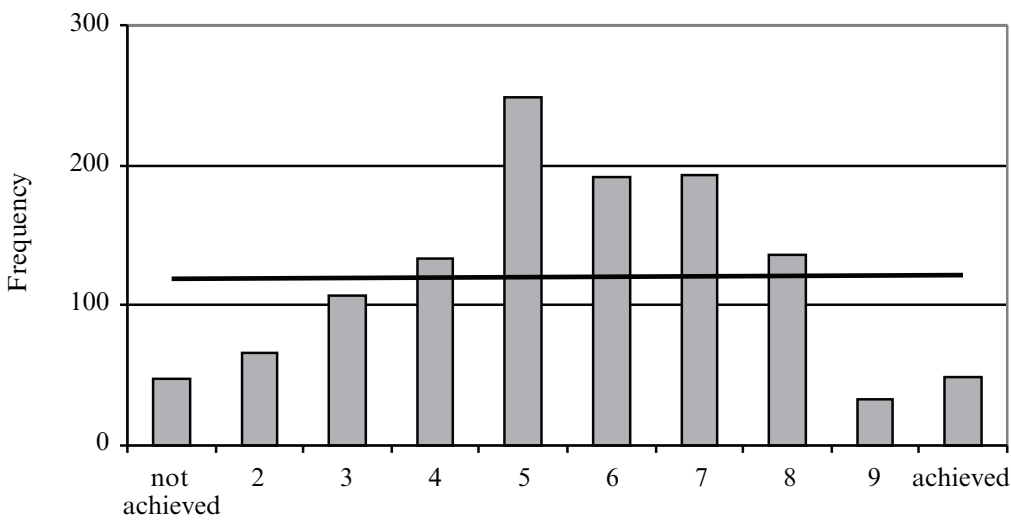

Notes: $N=1204$; mean $=5.52$; standard deviation $=2.142$.

Figure 2. Encouraging a shared society?

These findings are also reflected in a qualitative study which looked at the impact of segregation and sectarianism in Northern Ireland and found:

"In some areas there are greater levels of mixing, sharing and integrating, while in others the legacy of the past, of hostility, fear and mistrust dominate the wider social environment. In most social environments the process of avoidance still appears to dominate interactions between members of the two main communities" (Hamilton et al, 2008, page 153).

While these data tell us about people's perceptions of the status quo, they offer little normative insight into the kind of postconflict society they would like Northern Ireland to become (multicultural or intercultural) and their policy preferences to achieve such ambitions. It is to this that I now turn.

(c) Do people want a more integrated society?

At the general level the 2009 survey data indicate people's overwhelming support for 'mixing'. Respondents were asked the following question:

"Some people think that better relations between Protestants and Catholics in

Northern Ireland will only come about through more mixing of the two communities. Others think that better relations will only come about through more separation. Which comes closest to your views?"

Some $88 \%$ of respondents (total $N=1095$ ) indicated that better relations would result from more mixing and only $3 \%$ suggested better relations would come from more separation between the two main communities (the remainder of the respondents "could not choose").

Did this significant level of support for mixing vary across different age groups, community identities, and socioeconomic groupings? In other words, I am hypothesising that the variables age, religion, and socioeconomic grouping are important factors in determining whether or not respondents want a more integrated society. I therefore cross-tabulated the variable "support for mixing" with: age, religion, and social economic grouping of the respondents to establish if there were significant associations. The results were as follows:

- age $\times$ mixing or separation: $\chi^{2}(5)=4.67, p>0.05$

- religion $\times$ mixing or separation: $\chi^{2}(2)=2.56, p>0.05$

- social economic grouping $\times$ mixing or separation: $\chi^{2}(2)=15.4, p<0.05$, with Cramer's $\mathrm{V}=0.12$. 
These results indicate that age and religion are statistically independent of respondents' attitudes to greater mixing or separation. In other words, most respondents, regardless of their age or religion, supported greater mixing over a segregated society. There is, however, a significant association between social economic grouping and attitudes to greater mixing and separation. In the case of these two variables the Cramer's $V$ statistic (0.12) tells us that the strength of the relationship is weak (although unlikely to have happened by chance, $p<0.05$ ). By examining the adjusted residuals in the cross tabulation of the variables social economic grouping and mixing or separation, it is clear that unskilled and unemployed respondents are more likely to favour separation over mixing. Intuitively, this may be because they are already living in highly segregated communities, perhaps at either side of 'peace' walls, and their experience is that physical separation equates to security and protection of their homes.

(d) What constitutes 'greater mixing'?

So far these results tell us that people in Northern Ireland do not yet see it as a normal civic society in which all individuals are treated equally and where differences are resolved through dialogue. They express a high level of support for greater mixing and believe that this will result in better relations between Protestants and Catholics. This support for greater mixing is independent of people's age or religious background. Respondents are evenly split on whether the government is actively encouraging shared communities where people of all backgrounds can live, work, learn, and play together. Given these results, what in policy terms should the government be doing to capture the tide of support for a more integrated (intercultural) society which would give direction or focus to the 'motherhood and apple pie' menu outlined in Cohesion, Sharing and Integration (OFMdFM, 2010)?

The 2009 survey poses several questions which provide more detailed insights into cross-community contact and mixing. These questions probed respondents on their attitudes to greater mixing and their preferences for integrated or segregated: living, schools, working environment, leisure activities, and personal relationships. The answers to these questions provide an opportunity to conduct an exploratory factor analysis to see whether there are a number of dimensions in the data gathered on cross-community contact and mixing which would help us to understand people's detailed thinking. Factor analysis can also prioritise their preferences beyond the superficial but overwhelming support for greater mixing expressed above.

A principal component analysis with orthogonal rotation (varimax) was carried out on fourteen variables relating to respondents' views on a more mixed or integrated society (see table 1). The Kaiser-Meyer-Olin (KMO) measure verified the sampling adequacy for the analysis, $\mathrm{KMO}=0.79$, exceeding the recommended value of 0.6 , and the Bartlett's test of sphericity $\chi^{2}(91)=4527.0, p<0.001$ indicated that correlations between the variables were sufficiently large for a principal component analysis. An initial analysis revealed the presence of four components with eigenvalues exceeding Kaiser's criterion of 1 and, in combination, explained 57.78\% of the variance. An inspection of the scree plot justified the retention of four components for further investigation. To assist in the interpretation of these components, varimax rotation was performed. The rotated solution is shown in table 1 and illustrates a number of strong loadings. The variables that cluster on the same components suggest the following order of preference to achieve "greater mixing" or a more integrated (intercultural) society:

- Component 1: represents a preference for greater mixing in schools, work, and where people live.

- Component 2: improved relationships with the 'other' community (friends, relatives, neighbours). 
Table 1. Dimensions of a mixed/integrated society rotated component matrix.

\begin{tabular}{|c|c|c|c|c|}
\hline & \multicolumn{4}{|c|}{ Component } \\
\hline & 1 & 2 & 3 & 4 \\
\hline $\begin{array}{l}\text { In favour of more mixing in secondary/grammar } \\
\text { schools }\end{array}$ & 0.840 & & & \\
\hline In favour of mroe mixing where people work & 0.835 & & & \\
\hline In favour of more mixing in primary school & 0.811 & & & \\
\hline In favour of more mixing where people live & 0.793 & & & \\
\hline In favour of more mixing in leisure/sports activities & 0.785 & & & \\
\hline In favour of more mixing in marriages & 0.516 & & & \\
\hline How many friends are the same religion as you? & & 0.750 & & \\
\hline How many relatives are the same religion as you? & & 0.711 & & \\
\hline How many neighbours are the same religion as you? & & 0.659 & & \\
\hline Prefer mixed or own religion workplace & & & 0.771 & \\
\hline Prefer mixed or own religion neighbourhood & & & 0.708 & \\
\hline Prefer mixed or own religion school & & & 0.600 & \\
\hline $\begin{array}{l}\text { Most people mind if relative marries someone of } \\
\text { different religion }\end{array}$ & & & & 0.8 \\
\hline $\begin{array}{l}\text { You mind if relative marries someone of different } \\
\text { religion }\end{array}$ & & & & 0.70 \\
\hline
\end{tabular}

Notes: Extraction method: principal component analysis, rotation method: varimax with Kaiser normalisation.

- Component 3: more integrated living (work, neighbourhood and school).

- Component 4: more intimate relations with the 'other' community (mixed marriages). In summary, the data from the empirical analysis suggest a number of things. People in Northern Ireland do not perceive it to be a normal civic society in which all individuals are equal, where differences are resolved through dialogue, and where all people are treated impartially. They are evenly balanced on whether they believe the government is encouraging shared communities, where people of all backgrounds can live, learn, and play together. The majority $(88 \%)$ of people felt that better community relations would result from more mixing of the two communities. When asked what constituted greater mixing, they expressed a preference for: mixed schools, work places, and housing; improved relations with the "other" community; more integrated living; and more intimate relations (mixed marriages), respectively.

These ordered preferences make intuitive sense moving from greater mixing in the daily activities of people at school, work, and where they live through integrated lifestyles and ultimately mixed marriages. They also offer government the opportunity to focus, in a prioritised way, on public and social policies based on empirical public support for these ideas. Top of the list are two essential public services which are ripe for reform but have so far received limited attention from government-education and housing services in Northern Ireland. I offer two examples from these key services which illustrate the potential for greater integration in response to the public preferences outlined above. What is interesting is that both examples were initiated and largely funded by external organisations (Atlantic Philanthropies and the International Fund for Ireland) rather than through mainstream government departments. The first example illustrates a work-in-progress case of shared education and the second describes an initiative to promote mixed housing, managed by the Northern Ireland Housing Executive. 


\section{Shared education}

The education system in Northern Ireland is highly segregated along religious linesProtestant (controlled) schools and Catholic (maintained) schools make up most of the education provision. Integrated schools account for approximately $6.5 \%$ of the school population and there are a number of Irish-medium schools, mostly in the primary sector, where children are taught through the Irish language. The churches exercise considerable influence on the management of the schools as transferors and trustees representing the Protestant and Catholic sectors, respectively, on education and library boards and boards of governors. As table 2 illustrates, out of a total school population of just over 300000 children, $90 \%$ or more of all children attend either Protestant or Catholic schools. Although the Department of Education has since 1989, under the Education Reform (Northern Ireland) Order, a statutory duty to "encourage and facilitate" the development of integrated education, its incremental growth has been relatively modest. This is, despite the fact that there is evidence of its positive reconciliation effects amongst school children (McGlynn, 2007). As Hayes et al (2007, page 454) note: "attendance at a religiously integrated school ... has positive long term benefits in promoting a less sectarian stance on national identity and constitutional preferences." The integrated sector blames the Department of Education for capping numbers in their schools and the minister for refusing development proposals to build new integrated schools or transform existing schools. The department, in turn, faces a dilemma in trying to facilitate the growth of a small integrated sector in the midst of a declining overall market having regard to the adverse impact that new or transformed integrated schools can have on other schools in the area.

Previous research (Brocklehurst, 2006; Gallagher, 2004; Hayes and McAllister, 2009; Hughes, 2010) has indicated the problems associated with separate schools in Northern Ireland and the long-term effect on social attitudes. As Brocklehurst (2006, page 92) notes:

"The [separate] school is essentially a closed environment where potent sentiments expressed between children can ramify their notions of religious difference, and physical bullying and peer pressure can reinforce concepts of identity" (cited in Hughes et al, 2010).

The lack of significant growth in the integrated sector and the ongoing control which churches exert in protecting single-identity education prompted external funders (Atlantic Philanthropies and the International Fund for Ireland) to support an initiative entitled

Table 2. School types of pupils' religion in Northern Ireland [source: calculated from the Department of Education (Northern Ireland) statistics 2009/10].

\section{Protestant $(\%) \quad$ Catholic $(\%) \quad$ Others $(\%)$}

\section{Primary schools}

Controlled/Protestant schools Maintained/Catholic schools Integrated schools

Total

Postprimary schools

Controlled/Protestant schools Maintained/Catholic schools Integrated schools 10.0

Total

$\begin{array}{lll}93 & 4.7 & 82.7 \\ 1.3 & 91.5 & 6.7 \\ 5.7 & 3.8 & 10.6 \\ 100 & 100 & 100\end{array}$

\section{7 \\ 100}

\begin{tabular}{lll}
89.0 & 4.8 & \multicolumn{1}{c}{82.9} \\
1.0 & 89.3 & 4.0 \\
5.9 & 13.1 & \\
100 & 100 & 100 \\
$(n=56845)$ & $(n=76139)$ & $(n=14775)$
\end{tabular}




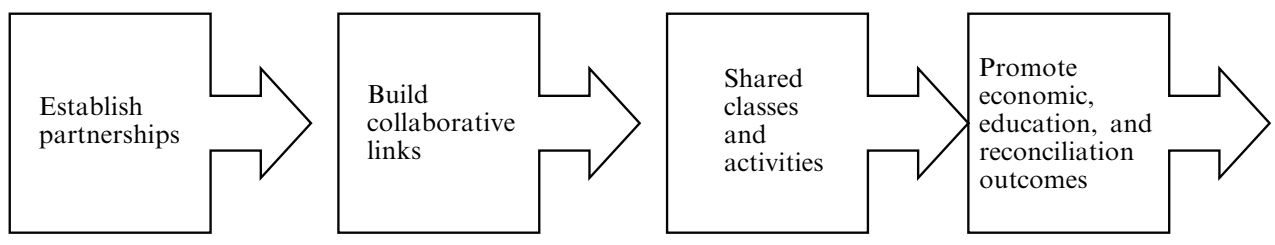

Figure 3. Sharing education model.

the 'Sharing Education Programme'. In 2007 they funded a three-year programme of twelve partnerships composed of sixty schools and 2500 pupils in Northern Ireland which collaborated on a cross-community basis to share classes and activities in order to improve education outcomes for pupils.

The underpinning model (see figure 3 ) involves cross-community collaboration based on sustained contact between pupils in the delivery of the curriculum in schools (Donnelly and Hughes, 2006; Hughes, 2007). The intention, unlike previous community relations initiatives in schools, is not to see joint activities as one-off extracurricular events but rather to put cross-community working at the heart of the process via the joint delivery of elements of the curriculum. Through collaboration, interdependencies develop across traditional school boundaries in a way which is nonthreatening. As a consequence, these boundaries become more porous and the distinctions which underpin existing structures are less relevant. Creating interdependencies demands rethinking the current system of autonomous school units with delegated budgets, whose success is based on competition for pupils. Rather, a networked approach is established offering mutual cross-community support. Parents endorse such collaboration because it improves the quality of their children's education, and who the provider is becomes less important to them.

At the end of the first phase of the Sharing Education Programme there has been an independent assessment of its impact (FGS McClure Watters, 2009). Key findings include the following:

- Those engaging in the Sharing Education Programme felt more comfortable in having contact with people from a different community.

- There was a greater willingness amongst participants to make more friends with pupils who belong to a different community background, both in school and outside of school.

- Participation in the programme resulted in pupils gaining new experiences and skills and increasing their level of confidence.

- Teachers concluded that participating on the programme provided direct educational benefits for pupils and afforded opportunities to build relationships with pupils from different community backgrounds and cultures.

- Curriculum development has been enhanced as a result of the programme.

In a qualitative study of teachers delivering the Sharing Education Programme, one comment captures a wide range of views held by those at the chalk face:

"The impact of the Sharing Education Programme is that it gives our kids an ongoing cross-community opportunity to meet regularly, to get to know each other, and to lift the clouds of suspicion that may have existed. They now believe that it is okay to be different and that it is okay to be yourself. I am convinced that those involved in the programme will be more likely to challenge prejudices either in their homes or beyond" (Knox, 2010, page 31).

Teachers also highlighted the many common issues that young people face regardless of their community background, which shared education can build on. Young people, 
for example, face pressures around drugs, alcohol, and social relationships. These issues transcend ethnic identity and can become a unifying platform to develop trust between pupils and a foundation for exploring more sensitive issues. Because of the success of the programme external funders have expanded and rolled out the initiative for a further three years throughout Northern Ireland involving around 150 schools and 13000 pupils.

\section{Shared housing}

The Northern Ireland Housing Executive is a nondepartmental public body within the Department of Social Development with a key role in managing the stock of existing social housing (some 90000 ). The Housing Executive is ultimately accountable to the Minister of Social Development and allocates social housing. This allocation process is not driven by a value judgment on the part of the Housing Executive between integrated or segregated housing but rather addressing need and accommodating people's choice of where to live. ${ }^{(2)}$ When faced with political instability and violence in the past, people had felt a strong sense of security living within their own communities ('amongst their own', to use the vernacular). However, as Murtagh argued, integration offers a number of advantages in terms of "social closure and mutual understanding, the growth of accommodated living space and the practical housing management benefits in the effective use of the stock, halting estate decline and providing safe access to services, facilities and job chances" (2001, page 783).

The Housing Executive recognised that community division and segregation prevented it from making best use of existing housing and land and made an explicit commitment in 2004/05 to support good relations through housing. One of its aims is to promote mixed housing where it is practicable, desirable, and safe. The Housing Executive established a Community Cohesion Unit to operationalise its commitment to improving community relations. The unit works on five core themes: flags, emblems, and sectional symbols; segregation and integration; race relations; interface areas; and communities in transition (Gray and McAnulty, 2006).

More recently (2008), the International Fund for Ireland launched the 'Shared Neighbourhood Programme' aimed at developing thirty shared neighbourhoods across Northern Ireland over a three year period.(3) The programme is led by communities working together to create shared spaces (Goodlad et al, 2005). It provides training and practical on-the-ground support through a dedicated team of cohesion advisers. In addition to grants to run official cultural awareness and community events, participating communities receive community relations training, community consultations, and support to design their own Neighbourhood Charter and deliver a good relations programme (International Fund for Ireland). Some sixteen communities are already involved after two years of the programme's operation.

This agenda was embraced enthusiastically by the (then) Social and Democratic Labour Party Minister for Social Development (Margaret Ritchie) who saw shared housing as central to her brief. In February 2008 she launched a new agenda for housing in Northern Ireland aimed at tackling the acute housing problem. The scale of the problem in stark statistical terms was set out as follows: over 38000 people on the house waiting list; over 20000 people in housing stress; over 9000 people officially homeless; and, average house prices over ten times average incomes (Ritchie, 2008a).

Central, however, to the delivery of this plan was the Minister's commitment to A Shared Future (OFMdFM, 2005). She noted that the Programme for Government 2008-11 (Northern Ireland Executive, 2008) had been criticised for the absence of a

(2) See http://www.nihe.gov.uk

(3) See http://www.intrenationalfundforireland.com/index.php 
specific commitment to $A$ Shared Future but made it clear that its principles would inform her approach to the housing agenda.

"The drive to increase affordable housing and shared neighbourhoods is close to my heart. The 'troubles' have created a legacy of communities living separately. A shared future will not merely evolve - it must be built. Divisions must be bridged, and as part of the new housing agenda, we aim to deliver as many newbuild social and affordable housing schemes as possible, in which the occupants are from mixed traditions and are signed up to a shared-future charter. The Shared Neighbourhood Programme will assist more communities in their desire to live together and involves communities and community organisations in 30 areas across Northern Ireland" (Ritchie, 2008b, page 120).

The minister's analysis was that although Northern Ireland had achieved a welcome level of political stability it was a dysfunctional society which was deeply segregated on sectarian lines where people lived, were educated, and socialised separately. She reasoned that to overcome this dysfunctionalism three things needed to happen: political stability, an improved economy, and social development. Shared housing was a key element in social development which should be a catalyst for transforming society and dismantling the institutionalised divisions and segregation that characterised Northern Ireland (Shirlow and Murtagh, 2006). The minister acknowledged that a shared ethos could not be forced.

To operationalise a shared future housing agenda the minister committed to deliver as many new build social and affordable housing schemes as possible, where occupants are from mixed traditions and are signed up to a 'Shared Future charter'. The prototype for this model was launched in Enniskillen (Carran Crescent), County Fermanagh where families signed up to a charter for their community which ensures that no more than $70 \%$ of any one religion is allowed. She also plans to convert many existing social housing developments to shared future status. Alongside this agenda for change, the minister committed to provided mixed tenure (private and social) housing as a way of achieving social and economic integration. Murtagh's research on integrated social housing concluded:

"New cross-community governance arrangements and the rediscovery of civic engagement are central to the sustainability of mixed housing schemes. But the need to capture these ideas as a coherent policy that considers the various ways in which integrated housing could increase choice and avoid segregation in different housing markets is an urgent priority" (2001, page 788).

Some time elapsed before integrated social housing became a priority and only then when the twin factors of external funding and a Minister enthused by $A$ Shared Future converged.

The significance of these two initiatives in key public services, education, and housing is that they illustrate the expressed preferences of people (from the survey data) in action. Shared education and housing have been piloted through funding from external organisations. Evidence is emerging that not only are these attractive options for parents, children, and residents, respectively, but they also offer real potential for a reconciled society in Northern Ireland [on links between education, housing, and segregation see Clark (1998) and Clark et al (1992)]. A more integrated society, at the heart of intercultural policy, is proving effective. This, in turn, poses an obvious question as to why the devolved government is not more active in promoting cross-community integration within public services. 


\section{Conclusions}

Does the wider research on community cohesion help us to understand what is happening in Northern Ireland? While community cohesion has challenged the whole notion of multiculturalism in terms of ethnic relations in Great Britain, the circumstances of minority-majority relations are different in Northern Ireland. This relationship is not based on ethnicity but on ethnonationalism, although minority ethnic relations have become problematic with the influx of new migrants. Cohesion, Sharing and Integration may be less about a new approach or policies aimed at promoting interculturalism and more crudely a political compromise brokered between the two main power-sharing parties in the wider interests of embedding devolution and stable government. It may also be about managing a divided society rather than about tackling the root causes, part of the legacy of violence where reconciliation comes before systemic changes.

The OFMdFM's 2010 consultation document Cohesion, Sharing and Integration tells us little about how the devolved government in Northern Ireland will operationalise its goals. It is well meaning and replete with good intentions pitched at a very general level- "we want a future based on sharing, equality, respect and understanding" were the two junior ministers' words at its launch. The document lacks priorities, and accountability for delivery amongst government departments, and makes no reference to allocated funding. It is difficult to see how it will "ensure good relations are embedded within all government policy making", one of its core themes for actions. Drawing on public attitudes data, I suggest that people do not yet see Northern Ireland as a normal civic society, express a high level of support for greater mixing (interculturalism), and are split as to whether the devolved government is actively encouraging shared communities. To do this, respondents have offered a hierarchy of policy choices in moving to a more integrated society in Northern Ireland, from greater mixing in daily activities of people at school, work, and where they live through integrated lifestyles and ultimately much greater acceptance of mixed marriages.

Yet government-run public services have largely eschewed integrated provision and tended to compound the status quo thus accentuating separation over sharing. The two examples of innovation in education and housing provision outlined in this paper have come from external funders. There is no suggestion that these provide the panacea for shared communities but evidence emerging from these projects is encouraging thus far. So why are politicians reluctant to embrace these ideas and mainstream sharing (interculturalism) in public services in a very explicit way in Cohesion, Sharing and Integration?

A number of factors seem plausible. While the public favour 'greater mixing', politicians may be less inclined. The empirical evidence that the public supports greater integration in principle needs some qualification. As Shirlow and Murtagh (2006) argue, there is a range of factors (beyond government policy) which may limit mobility. People feel safe living in their 'own' communities which have become self-sufficient through duplicated public services (schools, leisure centres, health clinics, etc). This, in turn, leads to a reluctance to shop and work outside their immediate areas. Their economic circumstances, since there is a high incidence of social deprivation in interface communities, will significantly limit their capacity to move to mixed areas. People have also developed strong neighbourhood and family bonds within segregated communities and may be reluctant to sever these kinship connections. Since the whole raison d'être for many of the political parties is based on ethnonational divisions, any blurring of these boundaries could negatively impact on their support base. Despite expressed public preferences for greater integration, the electoral support base for Sinn Féin and the DUP is strong. Voting patterns remain impervious to public policy issues 
because the legacy of voting on constitutional lines and fears of 'selling out' still exist. Yet a recent public statement by First Minister Peter Robinson that the education system in Northern Ireland is "a benign form of apartheid which is fundamentally damaging to our society" may indicate a shift in response to public opinion (Robinson, 2010, page 2).

Minor interventions in public services could make an enormous difference. For example, the Education (Northern Ireland) Order 2006 places a mandatory requirement on all postprimary schools to collaborate in the provision of a wider range of subjects by 2013. From that date, schools will be required to provide pupils with access to a minimum number of courses at Key Stage 4 (current target twenty four) and a minimum number of courses at post-16 (current target twenty seven). In both cases at least one third of the courses must be general (academic) and at least one third applied (vocational/professional/technical). Inexplicably, the Department of Education has not incentivised in any way cross-community collaboration in the implementation of the extended education curriculum. Cohesion, Sharing and Integration offers a suitable mechanism for the devolved government in Northern Ireland to meet the expressed needs of the people for a more integrated society, but not in its current format. It has merit because the consultation paper has the political imprimatur of the two largest political parties in government but is limited in ambition and lacks implementation details. Whether political self-preservation stymies the wishes of the public, remains to be seen. The public, it seems, are more willing to embrace interculturalism than politicians, many of whom still appear wedded to outdated ideas of 'separate but equal'.

\section{References}

Amin A, 2002, "Ethnicity and the multicultural city: living with diversity" Environment and Planning A $34959-980$

Bouchard G, Taylor C, 2008, "Building the future: a time for reconciliation", abridged report, Gouvernement du Québec, Québec

Brocklehurst H, 2006 Who's Afraid of Children? Children, Conflict and International Relations (Ashgate, Aldershot, Hants)

Burnett J, 2004, "Community, cohesion and the state" Race and Class 45(3) 1-18

Burnett J, 2007, "Book review. Britain's 'civilising project': community cohesion and core values" Policy and Politics $35353-357$

Cantle T, 2009, "Sleepwalking to segregation: challenging myths about race and migration" Journal of Social Policy $38709-711$

Chrisafis A, 2004, "Orchestrated attacks on minorities raise fears of ethnic cleansing: racist war of the loyalist street gangs" The Guardian 10 January, page 1

Clark W A V, 1988, "School integration impacts on residential change: evaluation and tests" Environment and Planning C: Government and Policy 6 475-488

Clark W A V, Dieleman F M, de Klerk L, 1992, "School segregation: managed integration or free choice?" Environment and Planning C: Government and Policy 1091 - 103

Community Cohesion Independent Review Team, 2001 Report of the Independent Review Team chaired by Ted Cantle (Home Office, London)

Community Relations Council, 2009 Towards Sustainable Security: Interface Barriers and the Legacy of Segregation in Belfast (CRC, Belfast)

Conway D, 2009 Disunited Kingdom: How the Government's Community Cohesion Agenda Undermines British Identity (Civitas, London)

Council of Europe, 2008 White Paper on Intercultural Dialogue 'Living Together as Equals in Dignity' (Council of Europe, Strasbourg)

Davenport M, 2010, “The shared future", http://www.bbc.co.uk/blogs/thereporters/ markdevenport/2010/07/the_shared_future.html

Deloitte, 2007 Research into the Financial Cost of the Northern Ireland Divide (Deloitte, Belfast)

Denham J, 2001 Building Cohesive Communities: A Report of the Ministerial Group on Public Order and Community Cohesion (Home Office, London) 
Donnelly C, Hughes J, 2006, "Contact, culture and context: evidence from mixed faith schools in Northern Ireland and Israel" Comparative Education 42493 - 516

Eatwell R, 2006, "Community cohesion and cumulative extremism in contemporary Britain" Political Quarterly $77204-216$

FGS McClure Watters, 2009 The Sharing Education Programme Consultancy Report (FGS, Belfast)

Finney N, Simpson L, 2009 Sleepwalking to Segregation: Challenging Myths About Race and Migration (Policy Press, Bristol)

Flint J, 2007, "Faith schools, multiculturalism and community cohesion: Muslim and Roman Catholic state schools in England and Scotland" Policy and Politics $35251-268$

Flint J, 2010, "Faith and housing in England: promoting community cohesion or contributing to urban segregation?" Journal of Ethnic and Migration Studies 36257 - 274

Flint J, Robinson D (Eds), 2008 Community Cohesion in Crisis: New Dimensions of Diversity and Difference (Policy Press, Bristol)

Gallagher T, 2004 Education in Divided Societies (Palgrave Macmillan, London)

Gavrielides T, 2010, "The new politics of community cohesion: making uses of human rights" Policy and Politics $38427-444$

Goodlad R, Burton P, Croft J, 2005, "Effectiveness at what? The processes and impact of community involvement in area-based initiatives" Environment and Planning C: Government and Policy $23923-938$

Gray P, McAnulty U, 2006, "Mixed housing", in Sharing over Separation: Actions Towards a Shared Future (Community Relations Council, Belfast) pp 67-94

Hamilton J, Hansson U, Bell J, Toucas S, 2008 Segregated Lives: Social Division, Sectarianism and Everyday Life in Northern Ireland (Institute for Conflict Research, Belfast)

Harris M, Young P, 2009, "Developing community and social cohesion through grassroots bridgebuilding: an exploration" Policy and Politics $37517-534$

Hayes B, McAllister I, 2009, "Education as a mechanism for conflict resolution in Northern Ireland" Oxford Review of Education 35437 - 450

Hayes B, McAllister I, Dowds L, 2007, "Integrated education, intergroup relations and political identities in Northern Ireland" Social Problems 54 454-482

Hughes J, 2007, "Mediating and moderating effects of inter-group contact: case studies from bilingual/bi-national schools in Israel" Journal of Ethnic and Migration Studies 33 419-437

Hughes J, 2009, "Peace and reconciliation and a shared future: a policy shift or more of the same?" Community Development Journal $4422-37$

Hughes J, 2010, "Are separate schools divisive? A case study from Northern Ireland" British Education Research Journal doi: 10.1080/0411926.2010.506943

Hughes J, Donnelly C, Gallagher T, Carlisle K, 2010 School Partnerships and Reconciliation: An Evaluation of School Collaboration in Northern Ireland (Queen's University, School of Education, Belfast)

Irish News 2010, "Opinion. Executive fails to grasp the nettle", 29 July, page 10

Kalra V, Kapoor N, 2009, "Interrogating segregation, integration and the community cohesion agenda" Journal of Ethnic and Migration Studies $351397-1415$

Kelly G, 2010, "Junior ministers launch consultation for Cohesion, Sharing and Integration", Press Release (Office of the First Minister and deputy First Minister, Belfast)

Knox C, 2010 Sharing Education Programme: Views from the White Board (University of Ulster, Jordanstown)

Knox C, Carmichael P, 2005, "Devolution - the Northern Ireland way: an exercise in "creative ambiguity" Environment and Planning C: Government and Policy 23 63-83

Kymlicka W, 2010, "The rise and fall of multiculturalism? New debates on inclusion and accommodation in diverse societies" International Social Science Journal $6197-112$

McGlynn C, 2007, "Rhetoric and reality: are integrated schools in Northern Ireland really making a difference?" Irish Educational Studies 26271 - 287

Mahood T, 2011, "This is not a minority problem: multiculturalism has made progress in Britain but white reticence is still the stumbling block" The Guardian 8 February, page 32

Murtagh B, 2001, "Integrated social housing in Northern Ireland" Housing Studies 16771 - 789

Northern Ireland Executive, 2008 Programme for Government 2008-2011 (Office of the First Minister and the deputy First Minister, Belfast)

OFMdFM, 2005 A Shared Future: Policy and Strategic Framework for Good Relations in Northern Ireland (Office of the First Minister and deputy First Minister, Belfast)

OFMdFM, 2010 Programme for Cohesion, Sharing and Integration: Consultation Document (Office of the First Minister and deputy First Minister, Belfast) 
Ouseley H, 2001 Community Pride, Not Prejudice Making Diversity Work in Bradford Bradford Vision, Bradford City Council, Bradford

Phillips D, 2006, "Parallel lives? Challenging discourses of British Muslim self-segregation" Environment and Planning D: Society and Space $2425-40$

PSNI, 2010, "Security situation statistics", Police Service of Northern Ireland, http://www.psni.police.uk/index/updates/updates_statistics/ updates_security_situation_and_public_order_statistics.htm

Rex J, 2010, "The concept of a multicultural society", in The Ethnicity Reader: Nationalism, Multiculturalism and Migration 2nd edition, Eds M Guibernau, J Rex (Polity Press, Cambridge) pp ...........

Ritchie M, 2008a, "Ritchie unveils new housing agenda for Northern Ireland", Department for Social Development, Press Release, 26 February, page 2

Ritchie M, 2008b, "New housing agenda" Hansard Official Record, 25 November, page 232

Robinson D, 2005, "The search for community cohesion: key themes and dominant concepts of the public policy agenda" Urban Studies $\mathbf{4 2} 1411$ - 1428

Robinson P, 2010, "First Minister argues for a single education system in Northern Ireland", speech to Castlereagh Council, 15 October, http://www.dup.org.uk

Shirlow P, Murtagh B, 2006 Belfast: Segregation, Violence and the City (Pluto Press, London)

The Belfast or Good Friday Agreement, 1998 Agreement Reached in Multi-party Negotiations (Northern Ireland Office, Belfast)

Thomas P, 2007, "Moving on from 'anti-racism'? Understandings of 'community cohesion' held by youth workers" Journal of Social Policy $36435-456$

Todd R, 1994, "Multiculturalism", in Dictionary of Race and Ethnic Relations 3rd edition, Ed. E Cashmore (Routledge, London)

Worley C, 2005, "It's not about race. It's about the community: New Labour and community cohesion" " Critical Social Policy $25483-496$

Wright O, Taylor J, 2011, "Cameron: my war on multiculturalism" The Independent 5 February, page 1 